\title{
Prone Position: Does It Help with Acute Respiratory Distress Syndrome (ARDS) Requiring Extracorporeal Membrane Oxygenation (ECMO)?
}

\author{
Nava Azimzadeh, Michael Baram, Nicholas C. Cavarocchi, Hitoshi Hirose \\ Division of Cardiothoracic Surgery and Division of Critical Care and Pulmonary Medicine, Thomas Jefferson University, \\ Philadelphia, PA, USA \\ Email: Hitoshi.Hirose@jefferson.edu
}

How to cite this paper: Azimzadeh, N., Baram, M., Cavarocchi, N.C. and Hirose, H. (2017) Prone Position: Does It Help with Acute Respiratory Distress Syndrome (ARDS) Requiring Extracorporeal Membrane Oxygenation (ECMO)? Open Journal of Respiratory Diseases, 7, 18-24. https://doi.org/10.4236/ojrd.2017.71003

Received: October 31, 2016

Accepted: December 26, 2016

Published: December 29, 2016

Copyright (๑) 2017 by authors and Scientific Research Publishing Inc. This work is licensed under the Creative Commons Attribution International License (CC BY 4.0).

http://creativecommons.org/licenses/by/4.0/

c) (i) Open Access

\begin{abstract}
Introduction: Lung protective ventilation therapy with low tidal volume-high PEEP is the standard treatment for the patients with acute respiratory distress syndrome (ARDS). Oscillators are occasionally used for salvage ventilation in cases where poor compliance restricts the use of traditional ventilation with ARDS. In addition to ventilator therapy, prone positioning has been used to improve oxygenation. We presented a challenging case of ARDS, which failed medical management extracorporeal membrane oxygenation (ECMO) support and oscillatory ventilation. Prone positioning was initiated which improved oxygenation, respiratory compliance and posterior atelectasis. Case presentation: A 41-year-old morbid obese female developed ARDS due to influenza pneumonia. The patient remained hypoxic despite optimum medical and ventilator management and required veno-venous extracorporeal membrane oxygenation (VV ECMO). CT scan of the chest showed ARDS with posterior consolidation. Despite ARDSnet ventilation support, antiviral therapy and ECMO support, there was no clinical improvement. High frequency oscillatory ventilation was initiated on ECMO day \#13, which resulted in no respiratory improvement over the next 5 days. On ECMO day \#18, the patient was placed on a Rotaprone ${ }^{\otimes}$ bed Therapy, utilizing a proning strategy of 16 hours a day. The clinical improvements observed were resolving of the consolidation on CXR, improvements in ventilatory parameters and decreased oxygen requirements. The patient was successfully weaned off ECMO on POD\#25 (8 days post prone bed). Conclusions: Prone position improved oxygen saturation and pulmonary compliance in severe ARDS requiring ECMO and it might facilitate early weaning.
\end{abstract}




\section{Keywords}

ARDS, Prone Position, ECMO, Hypoxia, Obesity

\section{Introduction}

Acute Respiratory distress syndrome (ARDS) has recently been re-defined by the Berlin criteria as severe hypoxemia, decreased lung compliance, and diffuse bilateral infiltration on chest X-ray. Patients with severe ARDS are managed with lung protective mechanical ventilation strategies which include low tidal volumes calculated to predicted body weight, high positive expiratory pressure (PEEP) with low targeting plateau pressure $<30 \mathrm{~cm} \mathrm{H}_{2} \mathrm{O}$. These respiratory settings have been used primarily for the patient with severe ARDS [1] and shown improved survival. However, lung protective ventilation strategy may not always provide satisfactory gas exchange. Another rescue mode of the ventilator setting used in ARDS involves high-frequency oscillatory ventilation (HFOV). High-frequency oscillatory ventilation is used to keep constant mean airway pressure by maintaining very small tidal volume $(1-3 \mathrm{~mL} /$ per breath) at a high frequency $(100 \mathrm{ml}$ breaths/min). Although Young et al. showed that oscillators should not be routinely used for ARDS, but it could be considered as a salvage modality [2]. In addition to these ventilator managements, prone position has been used in ARDS to improve oxygenation [3].

If ventilator management fails, extra corporeal membrane oxygenation (ECMO) should be considered as an advanced mode of therapy [4]. ECMO will provide oxygenation and $\mathrm{CO}_{2}$ clearance; however, ECMO itself will not treat primary disease condition, which requires diagnosis and management [5]. Various ventilator modes of management may be required to achieve successful outcomes after placement of ECMO for the patients with ARDS.

We presented a challenging case of ARDS due to influenza pneumonia in a morbidly obese patient, whose condition was deteriorating despite of combination therapy of VV ECMO, ARDSnet settings and eventually HFOV ventilation. We added prone positioning therapy for this patient, which improved respiratory status significantly and allowed us to wean from ECMO. This repots were approved our institutional review board (IRB, \#11D185) and consents were waived due to retrospective care report, per IRB.

\section{Case Presentation}

A 41-year-old morbid obese female (body mass index [BMI] $=56 \mathrm{~kg} / \mathrm{m}^{2}$ ) without significant past medical history presented to an emergency department with fever, shortness of breath and malaise. Initial therapy included anti-viral (Oseltamivir) and antibiotics (Azithromycin, Azrteonam and Vancomycin) as well as non-invasive respiratory management. Non-invasive management failed requiring intubated due to hypoxic respiratory failure. The patient was transferred to 
our institution for further management. Arterial blood gas (ABG) on arrival showed $\mathrm{pH}$ 7.15, $\mathrm{Pa} \mathrm{CO}_{2} 75 \mathrm{mmHg}, \mathrm{PaO}_{2} 40 \mathrm{mmHg}$, and oxygen saturation 73\% Mechanical ventilation mode (assist control) settings were: tidal volume $348 \mathrm{ml}$, respiratory rate 25/min, $\mathrm{FiO}_{2} 100 \%$ and PEEP $20 \mathrm{~mm} \mathrm{H}_{2} \mathrm{O}$; chest $\mathrm{x}$-ray showed bilateral infiltration, consistent with ARDS (Figure 1, left). Viral panel was positive for Influenza A. Medical management with ARDSnet ventilation settings, paralytics and Epoprostenol failed to improve $\mathrm{ABG}\left(\mathrm{PaO}_{2} 42 \mathrm{~mm} \mathrm{Hg}, \mathrm{PaCO}_{2} 75\right.$ $\mathrm{mm} \mathrm{Hg}$ with tidal volume $360 \mathrm{ml}$, respiratory rate $15 / \mathrm{min}, \mathrm{FiO}_{2} 100 \%$ and PEEP $20 \mathrm{~mm} \mathrm{H}_{2} \mathrm{O}$ ). Veno-venous ECMO (VV ECMO) was initiated using Avalon cannula [6]. CT scans taken after initial stabilization with VV ECMO showed severe posterior consolidations without pulmonary emboli (Figure 2, left).

At this time, prone bed was not utilized due to body habitus and weight of 138 Kg. Although both high frequency oscillatory ventilation (HFOV) and ECMO provided an acceptable oxygenation $\left(\mathrm{O}_{2}\right.$ Sat mean: $\left.96 \%\right)$, respiratory compliance

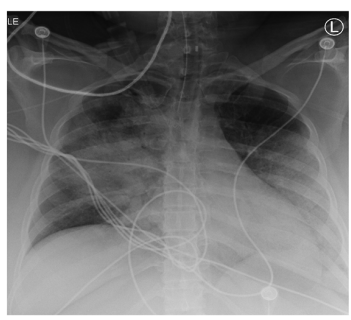

Before ECMO

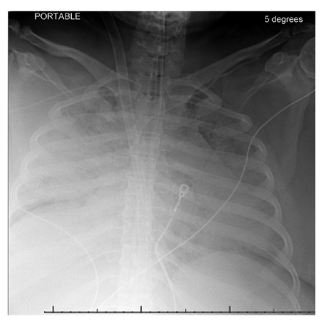

ECMO day \#1

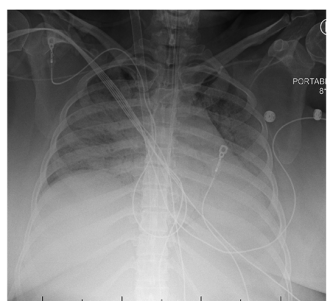

ECMO day \#12 (before oscillatory)

ECMO $\mathrm{FiO}_{2} 50 \%$ Sweep 7

Vent $\mathrm{FiO}_{2} 50 \%$ PEEP 7.5

$\mathrm{PaO}_{2} 60, \mathrm{PaCO}_{2} 41$

ABG: $\mathrm{PaO}_{2} 42, \mathrm{PaCO}_{2} 75$

$\mathrm{PaO}_{2} 46, \mathrm{PaCO}_{2} 43$

Figure 1. Chest X-rays, ventilator and ECMO setting, and ABG. Chest X-ray shows bilateral infiltration of the lungs.

Before prone

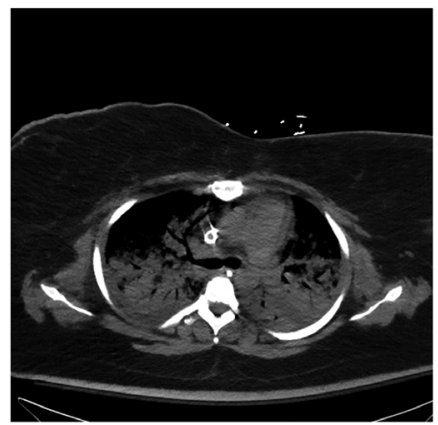

After prone

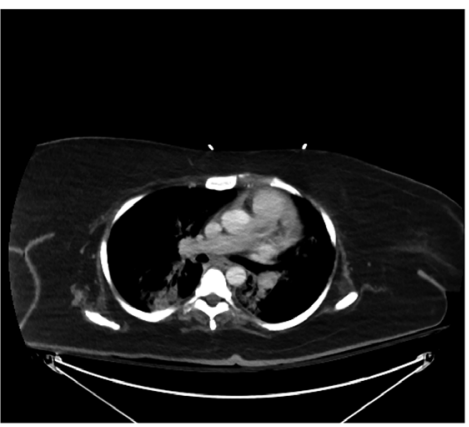

Figure 2. CT scan shows posterior consolidation before prone position. The posterior consolidation was improved after prone positioning. 
did not improve and remained $20 \mathrm{ml} / \mathrm{cm} \mathrm{H}_{2} \mathrm{O}$. The chest X-ray demonstrated no improvement over 12 days on ECMO (Figure 1, right). HFOV was initiated on post-ECMO day \#13. The patient's oxygenation and chest X-ray findings remained unchanged in the next 5 days (Figure 3, left). On ECMO day \#18, the patient was placed on a Rotaprone ${ }^{\mathrm{max}}$ bed (KCI, San Antonio, TX), accepting the risk of compression of the thorax due to the body habitus (large breasts) and excessive BMI. The patient's vital signs were closely monitored during prone position (16 hours a day) and supine position (8 hours a day) (Figure 4 ). The patient's respiratory status improved from the first day of prone position. Consolidations on chest X-ray were significantly improved (Figure 3, middle and right).

Oxygen saturation significantly improved in prone position (average $84 \%$ in supine position vs. $99 \%$ in prone position (Figure 5). Oxygen saturation showed

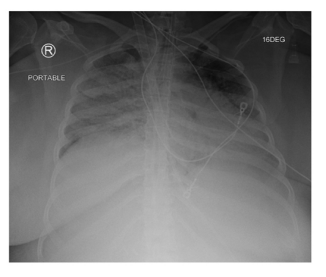

ECMO day \#17

(Pre-prone)

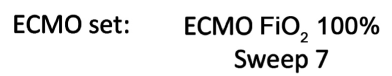

Vent set:

Vent $\mathrm{FiO}_{2} 100 \%$ Oscillator amp 63

ABG: $\mathrm{PaO} 276, \mathrm{PaCO}_{2} 45$

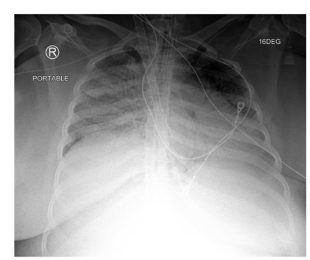

ECMO day \#20 (Prone day \#3)

ECMO $\mathrm{FiO}_{2} 50 \%$ Sweep 7

Vent $\mathrm{FiO}_{2} 50 \%$ Oscillator amp 58

$\mathrm{PaO} 2$ 81, $\mathrm{PaCO}_{2} 41$

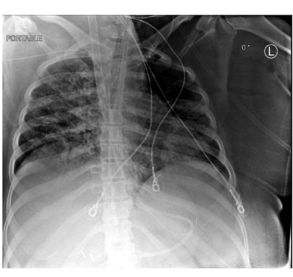

ECMO day \#25

(Prone day \#8) Before decannulation

ECMO $\mathrm{FiO}_{2} 50 \%$ Sweep 3

Vent $\mathrm{FiO}_{2} \mathbf{5 0 \%}$ PEEP 14

$\mathrm{PaO} 2$ 142, $\mathrm{PaCO}_{2} 42$

Figure 3. Significant improvement of lung infiltration after prone position.

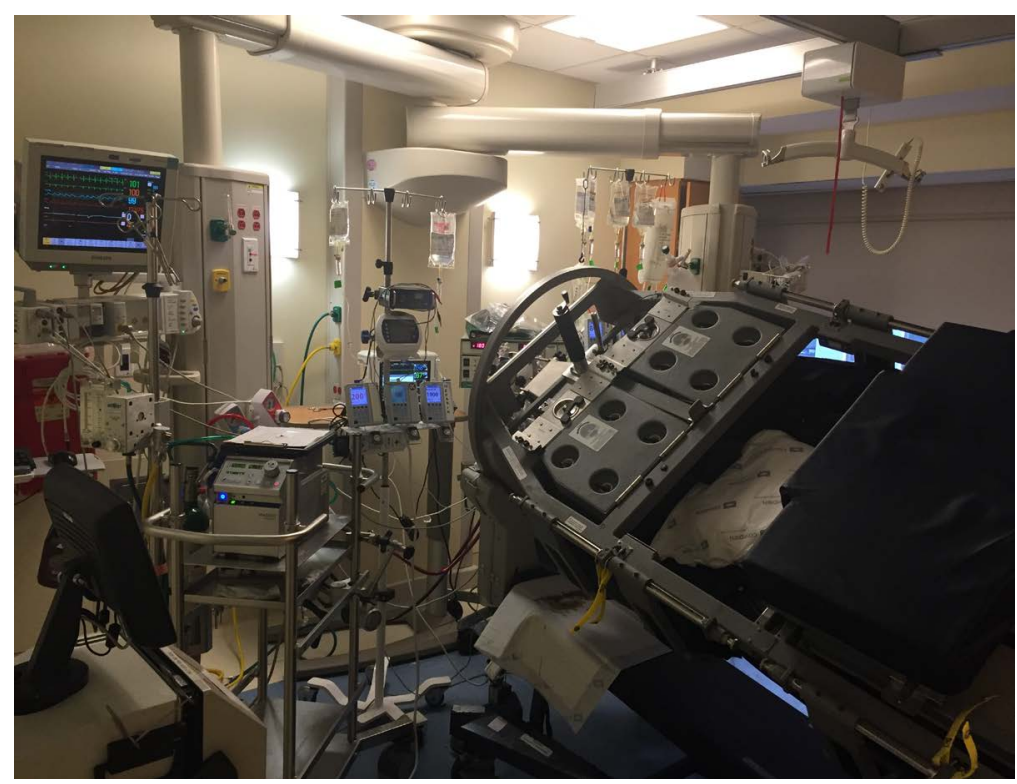

Figure 4. Rotaprone bed with ECMO. 
significant increase during hours of prone position compared to hours on supine position. Respiratory compliance improved from 12 to $24-\mathrm{ml} / \mathrm{cm} \mathrm{H}_{2} \mathrm{O}$ and mean airway pressure was improved from 26 to $13 \mathrm{~cm} \mathrm{H}_{2} \mathrm{O}$ (Figure 6). $\mathrm{ECMO} \mathrm{FiO}_{2}$ was able to decrease to $50 \%$ on 3rd day of the prone position, and ECMO sweep was decreased to minimum on prone day \#6. The patient was taken off the prone bed and underwent ECMO decannulation on ECMO day \#25 (prone day \# 8). At the time of decannulation $\mathrm{ABG}$ was $\mathrm{pH} 7.36 \mathrm{PaO}_{2} 142 \mathrm{mmHg}, \mathrm{Pa} \mathrm{CO}_{2} 42 \mathrm{mmHg}$, with $\mathrm{ECMO} \mathrm{FiO}_{2} 50 \%$, sweep $3 \mathrm{l} / \mathrm{min}$ and ventilator $\mathrm{FiO}_{2} 50 \%$, PEEP $14 \mathrm{~cm} \mathrm{H}_{2} \mathrm{O}$. The posterior consolidation was completely resolved with prone bed (Figure 2, right). The patient underwent tracheostomy due to ventilator dependent respiratory failure and she was transferred to rehabilitation facility for long-term ventilator weaning.

$\mathrm{O}_{2}$ saturation while on supine vs. prone

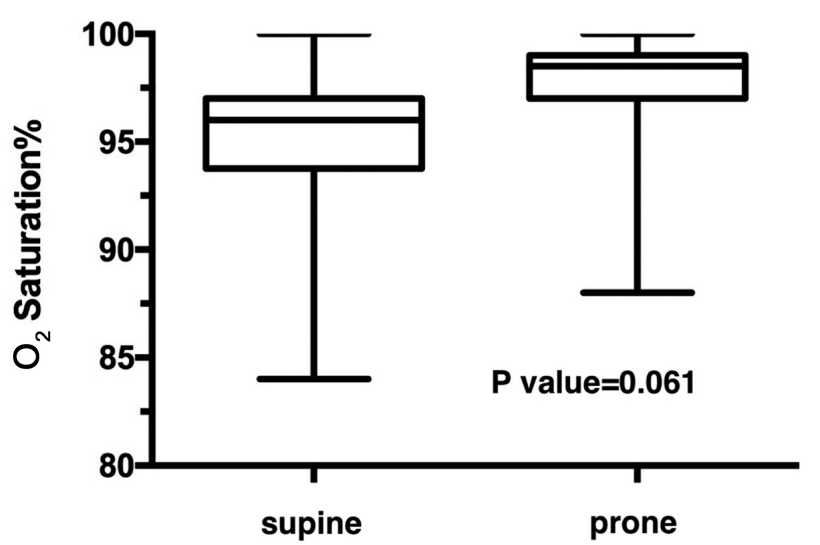

Figure 5. Average oxygen saturation in supine position vs. prone position.

Trend of mean airway pressure $\left(\mathrm{cm} \mathrm{H}_{2} \mathrm{O}\right)$

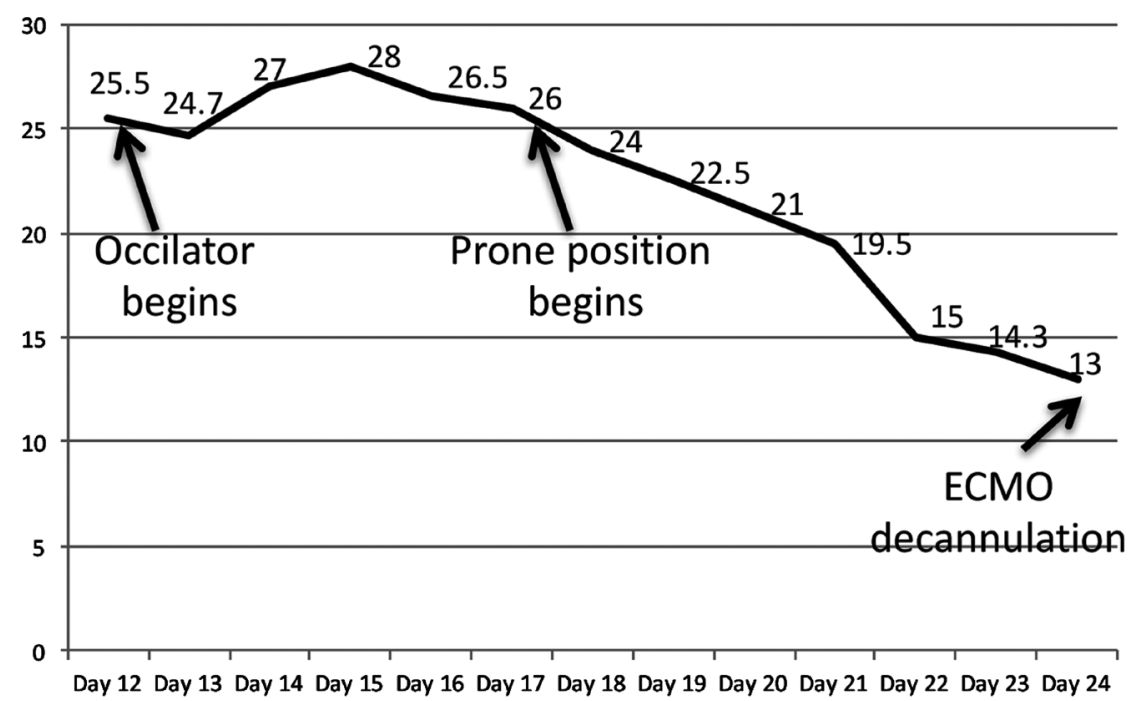

Figure 6. Trend of mean airway pressure on ECMO. 


\section{Discussion}

Despite improvement of understanding pathophysiology and management of ARDS, mortality rate of ARDS remains high, varying between 27\% and 45\% [7]. Prone position has been used for nearly four decades in patients with ARDS. Many mechanisms have been proposed to explain this effect, including drainage of secretions, improved ventilation perfusion matching, alveolar recruitment and even gravitational gradient in pleural space [1]. VV ECMO is a salvage strategy in ARDS patients failing conventional therapy. Few studies demonstrated that combination of prone position therapy and ECMO to improve the clinical outcomes [8]. Earlier, we reported a case of tracheal injury who was successfully managed by simultaneous ECMO, high frequency oscillator ventilation, and prone position [9].

Previously, Guervilly studied fifteen patients with severe ARDS on VV-ECMO placed on prone positioning [10]. These patients had severe hypoxemia $\left(\mathrm{PaO}_{2} /\right.$ $\mathrm{FiO}_{2}$ ratio below 70) despite maximal oxygenation, plateau pressure exceeding $32 \mathrm{~cm} \mathrm{H}_{2} \mathrm{O}$ or failure of try to wean ECMO after at least 10 days on ECMO. In this study, Guervilly reported that prone positioning improved $\mathrm{PaO}_{2} / \mathrm{FiO}_{2}$ ratio and respiratory compliance significantly. Based on improvement of oxygenation by prone positioning, this process may facilitate weaning of ECMO.

Possible complications related to prone positions includes cannula dislocation, intravenous line dislodgement, pressure injury to the torso, need for increased sedation, airway obstruction, displacement of endotracheal tube, and swelling of the face. Contraindication of prone positioning includes weight $>350$ $\mathrm{lb}$, multiple trauma patients, severe facial injury, and unstable spine fractures. The patient reported here was not initially placed on prone position due to excess BMI and large breasts. The patient's respiratory status could have gotten worse due to increased intra-abdominal pressure and chest compression. Interestingly a few studies showed that obese patients with ARDS even benefit more on prone position [11]. The concern of the thoracic compression from body habitus (large breasts) and excessive BMI could be well managed with the Rotaprone ${ }^{\mathrm{Tm}}$ bed. The immediate effects of positioning therapy in our patients were reported by close monitoring during prolonged prone and supine position in comparison.

While strong clinical data is still lacking to support the conclusion that all morbidly obese patients with severe ARDS on ECMO benefit from prone positioning, additional studies are needed to assess the efficacy and adverse effects of positioning therapy in combination with VV-ECMO in patients with ARDS.

\section{Conclusion}

Prone position improved oxygen saturation and pulmonary compliance in severe ARDS requiring ECMO. Potential complications of prone position in an obese patient can be managed using a Rotaprone bed.

\section{References}

[1] Thompson, B.T. and Bernard, G.R. (2011) ARDS Network (NHLBI) Studies: Suc- 
cesses and Challenges in ARDS Clinical Research. Critical Care Clinics, 27, 459-468. https://doi.org/10.1016/j.ccc.2011.05.011

[2] Young, D., Lamb, S.E., Shah, S., MacKenzie, I., Tunnicliffe, W., Lall, R., et al. (2013) High-Frequency Oscillation for Acute Respiratory Distress Syndrome. The New England Journal of Medicine, 368, 806-813. https://doi.org/10.1056/NEJMoa1215716

[3] Kimmoun, A., Roche, S., Bridey, C., Vanhuyse, F., Fay, R., Girerd, N., et al. (2015) Prolonged Prone Positioning under VV-ECMO Is Safe and Improves Oxygenation and Respiratory Compliance. Annals of Intensive Care, 5, 35. https://doi.org/10.1186/s13613-015-0078-4

[4] Shekar, K., Davies, A.R., Mullany, D.V., Tiruvoipati, R. and Fraser, J.F. (2013) To Ventilate, Oscillate, or Cannulate? Journal of Critical Care, 28, 655-662. https://doi.org/10.1016/j.jcrc.2013.04.009

[5] Tojo, K., Nagamine, Y., Yazawa, T., Mihara, T., Baba, Y., Ota, S., Goto, T. and Kurahashi, K. (2015) Atelectasis Causes Alveolar Hypoxia-Induced Inflammation during Uneven Mechanical Ventilation in Rats. Intensive Care Medicine Experimental, 3, 56. https://doi.org/10.1186/s40635-015-0056-Z

[6] Shaheen, A., Tanaka, D., Cavarocchi, N.C. and Hirose, H. (2016) Veno-Venous Extracorporeal Membrane Oxygenation (VV ECMO): Indications, Preprocedural Considerations, and Technique. Journal of Cardiac Surgery, 31, 248-252. https://doi.org/10.1111/jocs. 12690

[7] Villar, J., Sulemanji, D. and Kacmarek, R.M. (2014) The Acute Respiratory Distress Syndrome: Incidence and Mortality, Has It Changed? Current Opinion in Critical Care, 20, 3-9. https://doi.org/10.1097/MCC.0000000000000057

[8] Kredel, M., Bischof, L., Wurmb, T.E., Roewer, N. and Muellenbach, R.M. (2014) Combination of Positioning Therapy and Venovenous Extracorporeal Membrane Oxygenation in ARDS Patients. Perfusion, 29, 171-177. https://doi.org/10.1177/0267659113502834

[9] Johnson, A.P., Cavarocchi, N.C. and Hirose, H. (2015) Ventilator Strategies for VV ECMO Management with Concomitant Tracheal Injury and H1N1 Influenza. Heart, Lung and Vessels, 7, 74-80. https://doi.org/10.1016/j.healun.2015.01.192

[10] Guervilly, C., Hraiech, S., Gariboldi, V., Xeridat, F., Dizier, S., Toesca, R., et al. (2014) Prone Positioning during Veno-Venous Extracorporeal Membrane Oxygenation for Severe Acute Respiratory Distress Syndrome in Adults. Minerva Anestesiologica, 80, 307-313.

[11] De Jong, A., Molinari, N., Sebbane, M., Prades, A., Futier, E., Jung, B., et al. (2013) Feasibility and Effectiveness of Prone Position in Morbidly Obese Patients with ARDS: A Case-Control Clinical Study. Chest, 143, 1554-1561.

https://doi.org/10.1378/chest.12-2115 
Submit or recommend next manuscript to SCIRP and we will provide best service for you:

Accepting pre-submission inquiries through Email, Facebook, LinkedIn, Twitter, etc. A wide selection of journals (inclusive of 9 subjects, more than 200 journals)

Providing 24-hour high-quality service

User-friendly online submission system

Fair and swift peer-review system

Efficient typesetting and proofreading procedure

Display of the result of downloads and visits, as well as the number of cited articles Maximum dissemination of your research work

Submit your manuscript at: http://papersubmission.scirp.org/

Or contact ojrd@scirp.org 